Citation: Yümün, Z. Ü., Kam, E., Önce, M, "Analysis of Toxic Element with Icp-Oes and Libs Methods in Marine Sediments Around the Sea of Marmara in Kapidağ Peninsula". Journal of Engineering Technology and Applied Sciences 4 (1) 2019 : 43-50.

\title{
ANALYSIS OF TOXIC ELEMENT WITH ICP-OES AND LIBS METHODS IN MARINE SEDIMENTS AROUND THE SEA OF MARMARA IN KAPIDAĞ PENINSULA
}

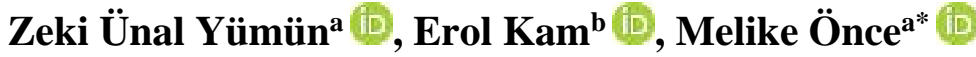 \\ ${ }^{a}$ Department of Enviromental Engineering Faculty of Çorlu Engineering, Tekirda ğ Namık Kemal \\ Universitesi Çorlu, Tekirdağ, Turkey, \\ zyumun@nku.edu.tr, monce@nku.edu.tr (*corresponding author) \\ ${ }^{b}$ Department of Physics Faculty of Arts and Sciences, Yildiz Technical University, İstanbul, Turkey, \\ erolkam@yildiz.edu.tr
}

\begin{abstract}
In this work, the LIBS (Laser Induced Breakdown Spectroscopy) and ICP-OES technique has been applied to the determination of total contents of heavy metals (Fe, $\mathrm{Zn}, \mathrm{Al}, \mathrm{Mn}, \mathrm{Co}, \mathrm{Cr}, \mathrm{Cu}, \mathrm{Ni}, \mathrm{Na}$, $\mathrm{Mg}, \mathrm{K}, \mathrm{Ca}$ ) in soil samples of Marmara Sea. In order to validate the technique, LIBS data were compared with data obtained on the same soil samples by application of conventional Inductively Coupled Plasma ICP spectroscopy. The partial agreement obtained between the two sets of data suggested the potential applicability of the LIBS technique to the measurement of heavy metals in soils.

According to the results, it was seen that the elements determined by ICP-OES analysis were also determined by LIBS method. The LIBS method is an important and practical technique for determining the elements that are enriched with anthropogenic factors as well as the elements resulting from natural processes.
\end{abstract}

Key words: LIBS, ICP-OES, Marmara Sea, Toxic Element

\section{Introduction}

Sediment is a chemically-complex matrix which contains almost all the elements. In marine environments, sediments have a very important role as they create a living and nutrient environment for many living things. In particular, living creatures that cannot move more or less on their own, live in sediment. The sea is a living environment that is a source of nutrition 
and water for living things. But it has also been the receiving environment in which waste can be disposed within industries and cities. This process has been increasing uncontrollably with the rapid development of the industry. Due to the longtime application of sewage sludge, livestock manure and industrial wastewater irrigation in the agricultural land, heavy metal contamination in sea sediments has become more serious [1].

Biodegradable toxic pollutants such as heavy metals accumulate in the marine environment and accumulate in the sediment. Pollutants accumulated in the sediment poison both sediments and living things because they are not biodegradable. The determination of the concentrations of these toxic elements which are involved in marine environment is very important for the environment and living health. In recent years, the LIBS method has been used to analyze toxic elements rather than traditional methods such as ICP-OES ([2],[3],[4]).

Conventional atomic spectroscopic techniques have excellent analytical performance, but their sample preparation method is difficult. As an atomic emission spectroscopy technique, LIBS is especially much good at metal analysis. LIBS, is an insitu method which can analyze solids, liquids and gases and provides versatile detection options with minimum sample preparation processes [5]. Therefore, studies about soil analysis were mainly focused on metals [6].

LIBS is a recent analytical technique that is based upon the measurement of emission lines generated by atomic species close to the surface of the sample, thus allowing their chemical identification ([6], [7], [8], [9]).

The main advantage of LIBS is to using the conventional methodology by avoiding laborious chemical steps, e.g., the preparation and dissolution of the soil sample. LIBS method has been used in many different studies (both qualitative and semi quantitative analysis, including environmental monitoring, industrial monitoring, biological, geological and agricultural materials) in previous years ([10],[11], [12], [13], [14], [15])

In this work, the LIBS technique has been applied to the determination of total contents of heavy metals (Fe, $\mathrm{Zn}, \mathrm{Al}, \mathrm{Mn}, \mathrm{Co}, \mathrm{Cr}, \mathrm{Cu}, \mathrm{Ni}, \mathrm{Na}, \mathrm{Mg}, \mathrm{K}, \mathrm{Ca}$ ) in a number of reference soil samples. In order to validate the technique, LIBS data were compared with data obtained on the same soil samples by application of conventional Inductively Coupled Plasma ICP spectroscopy [16].

\section{Materials and method}

In this work, twelve core sediments samples have been examined. Samples were taken from Kapıdağ peninsula and Gulf of Erdek. The soil samples were selected on the basis of their representativity of investigation area. The coordinates of the samples are given in Table 1 and the location map are shown in Figure 1. 
Table 1. Sample coordinates of the work area

\begin{tabular}{|c|c|c|c|c|}
\hline \multirow{2}{*}{$\begin{array}{l}\text { CORE } \\
\text { SAMPLE } \\
\text { NO }\end{array}$} & \multirow[t]{2}{*}{ GPS NO } & \multirow[t]{2}{*}{$\begin{array}{l}\text { DEPTH } \\
(\mathrm{m})\end{array}$} & \multicolumn{2}{|c|}{$\begin{array}{l}\text { GEOGRAPHIC POSITION } \\
\text { (WGS-84) }\end{array}$} \\
\hline & & & $\mathbf{Y}$ & $\mathbf{X}$ \\
\hline Core 1 & GPS 116 & 30 & 0581459 & 4474677 \\
\hline Core 2 & GPS 117 & 29 & 0584985 & 4476692 \\
\hline Core 3 & GPS 119 & 30 & 0588105 & 4481639 \\
\hline Core 3 & GPS 120 & 35 & 0586229 & 4482780 \\
\hline Core 4 & GPS 121 & 30 & 0582393 & 4483551 \\
\hline Core 5 & GPS 125 & 38 & 0577401 & 4485335 \\
\hline Core 6 & GPS 126 & 40 & 0566840 & 4486334 \\
\hline Core 7 & GPS 127 & 48 & 0562101 & 4486810 \\
\hline Core 8 & GPS 128 & 39 & 0558197 & 4484862 \\
\hline Core 9 & GPS 129 & 28 & 0558282 & 4480129 \\
\hline Core 10 & GPS 138 & 19 & 0556281 & 4463687 \\
\hline Core 11 & GPS 139 & 26 & 0542436 & 4464634 \\
\hline Core 12 & GPS 140 & 11 & 0531959 & 4471035 \\
\hline
\end{tabular}

The first element analysis of (Fe, $\mathrm{Zn}, \mathrm{Al}, \mathrm{Mn}, \mathrm{Co}, \mathrm{Cr}, \mathrm{Cu}, \mathrm{Ni}, \mathrm{Na}, \mathrm{Mg}, \mathrm{K}, \mathrm{Ca}$ ) the samples taken from the sediment samples obtained from the study area was carried out in the Scientific and Technological Research and Application Center of Namık Kemal University using the ICP-OES device [17]. Within the scope of these analyzes, firstly sediment samples have been dried and pounded using mortar. These samples have been separated as 0,5 gr. The collected samples are placed in incineration tubes and burned for 1 hour at $98^{\circ} \mathrm{C}$ and 1.5 hours at $200^{\circ} \mathrm{C}$ by adding $12 \mathrm{~mL} \mathrm{HNO}_{3}$ and $4 \mathrm{~mL} \mathrm{HCl}$. After the lids of the cooling tubes have been pulled out in the furnace, it has been completed to $50 \mathrm{~mL}$ with ultrapure water and filtered using filter papers. Geochemical analyses of these samples have been performed using ICP-OS device. The prepared samples have been placed in the measurement unit of the ICP-OS device and readings made ([18], [17], [19]). 


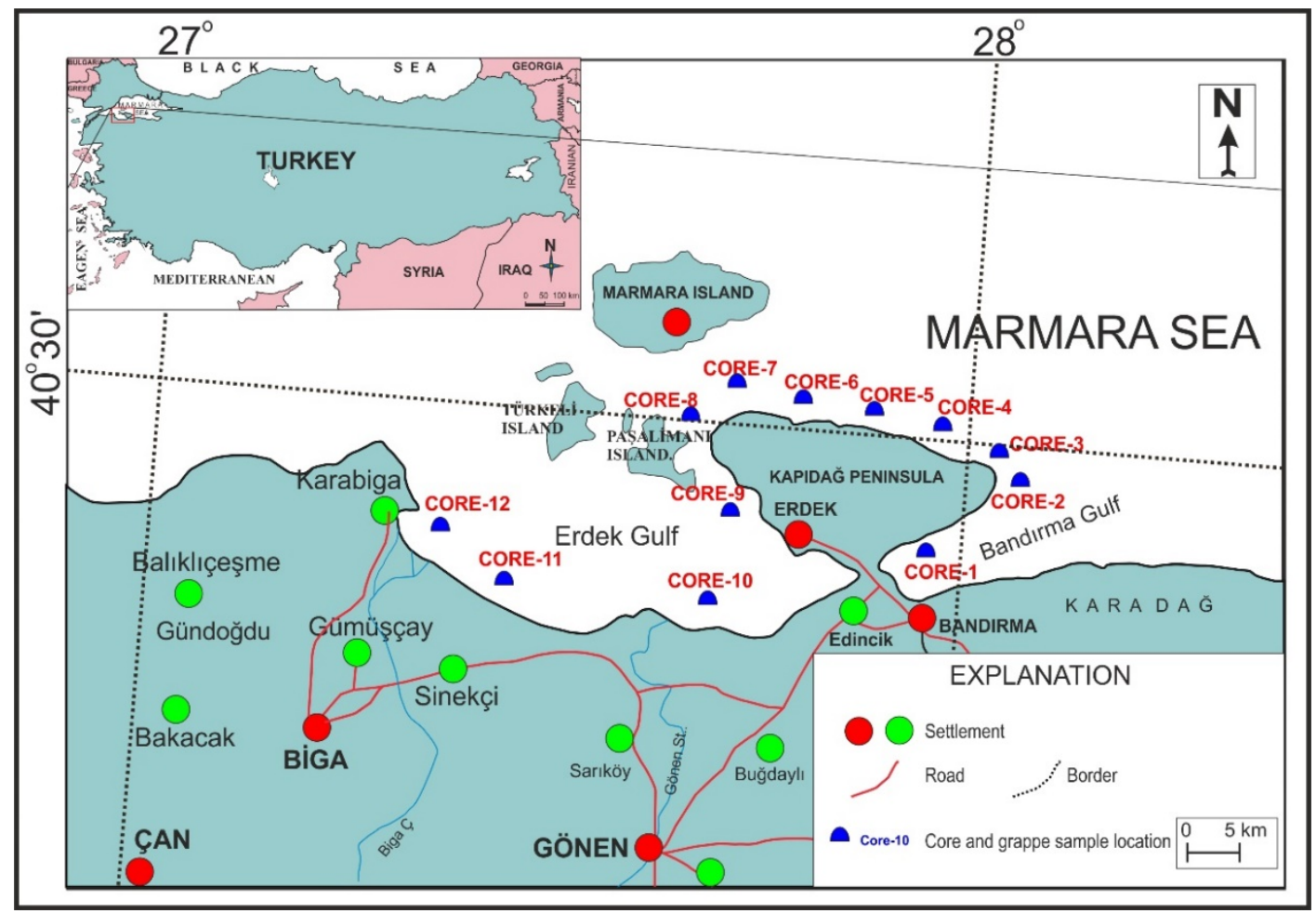

Figure 1. Location map of investigation area

The second method of analysis is LIBS. Laser Induced Plasma Spectroscopy (ICP-OES) is an optical emission spectroscopy method used for multi-elemental analysis of materials. In LIBS technique, a focused, high intensity pulsed laser beam is impinged on the target solid surface under investigation. As a result, a near-surface high-density plasma plume is formed, which expands into the ambient atmosphere [20]. The optimum instrumental parameters for soil analysis have been obtained when repetition rate, td, and tw equaled $10 \mathrm{~Hz}, 1 \mu \mathrm{s}$, and $10 \mu \mathrm{s}$, respectively. Standard reference material (SRM-2586) has been used to prepare pellets for the parameter analysis [21]. Samples taken from the same levels have been placed into the pellet container which is 20-25 gr and pressed for 5 seconds in the press machine under a pressure of approximately 100 bar. This form of samples is called the pellet. The pelletized samples have been placed in locked pouches and sent to the LİBS analysis [22].

\section{Findings}

The results of ICP-OES analysis of the study area have been given in Table 2 and the results of LIBS method also in Table 3. 
Tablo 2. ICP-OES analysis results of core samples

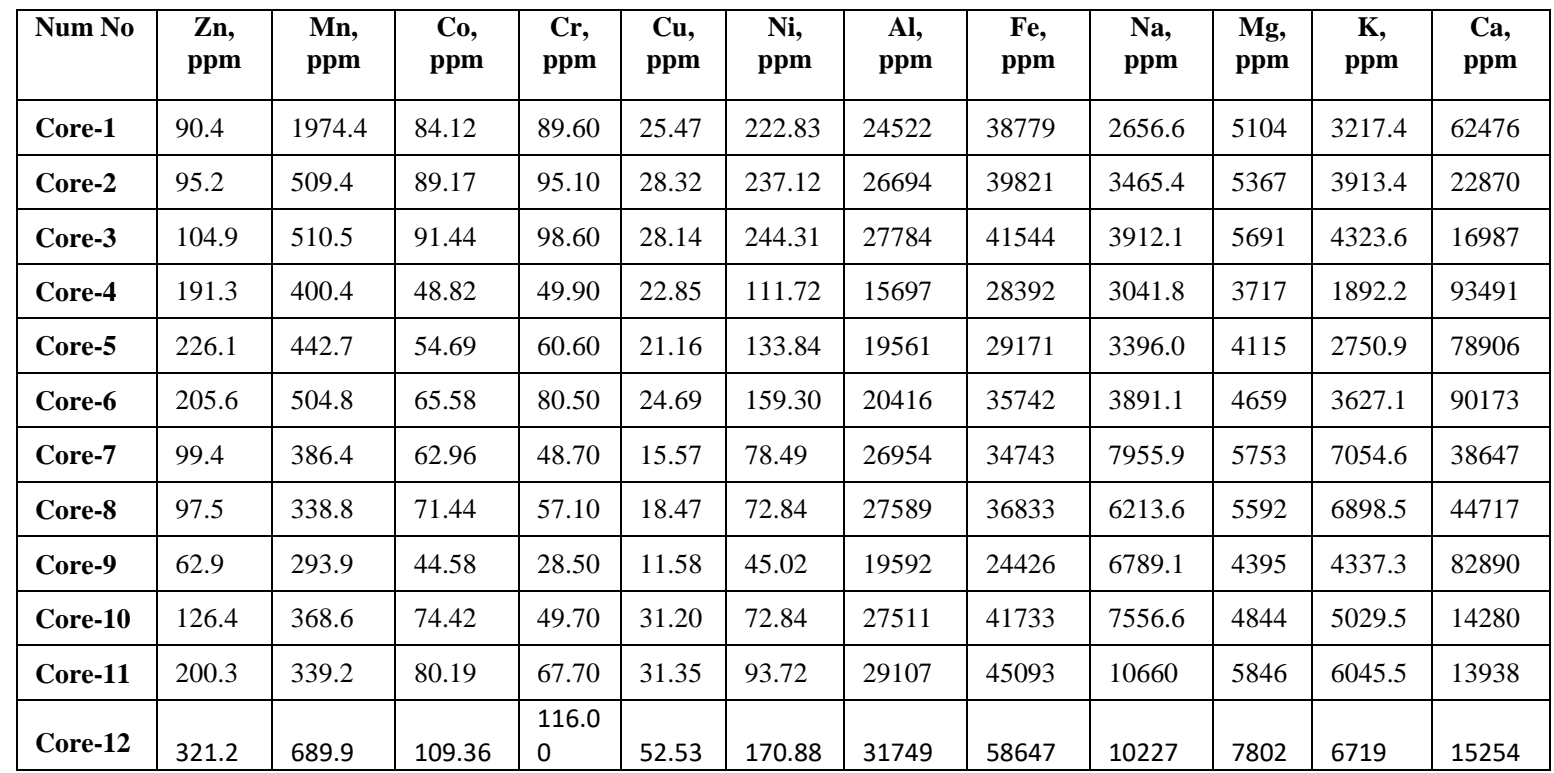

Tablo 3. LIBS analysis results of core samples

\begin{tabular}{|l|c|c|c|c|c|c|c|c|c|c|c|c|}
\hline $\begin{array}{l}\text { Num } \\
\text { No }\end{array}$ & $\begin{array}{c}\text { Zn } \\
\mathbf{( \% )}\end{array}$ & $\begin{array}{c}\mathbf{M n} \\
\mathbf{( \% )}\end{array}$ & $\begin{array}{c}\mathbf{C o} \\
\mathbf{( \% )}\end{array}$ & $\begin{array}{c}\mathbf{C r} \\
\mathbf{( \% )}\end{array}$ & $\begin{array}{c}\mathbf{C u} \\
\mathbf{( \% )}\end{array}$ & $\begin{array}{c}\mathbf{N i} \\
\mathbf{( \% )}\end{array}$ & $\begin{array}{c}\mathbf{A l} \\
\mathbf{( \% )}\end{array}$ & $\begin{array}{c}\mathbf{F e} \\
\mathbf{( \% )}\end{array}$ & $\begin{array}{c}\mathbf{N a} \\
\mathbf{( \% )}\end{array}$ & $\begin{array}{c}\mathbf{M g} \\
\mathbf{( \% )}\end{array}$ & $\begin{array}{c}\mathbf{K} \\
\mathbf{( \% )}\end{array}$ & $\begin{array}{c}\text { Ca } \\
\mathbf{( \% )}\end{array}$ \\
\hline Core-1 & 10 & 25 & 15 & 20 & 10 & 3 & 75 & 95 & 80 & 90 & 95 & 75 \\
\hline Core-2 & 8 & 27 & 18 & 21 & 11 & 4 & 73 & 96 & 70 & 90 & 95 & 76 \\
\hline Core-3 & 8 & 20 & 16 & 31 & 11 & 3 & 69 & 94 & 75 & 89 & 86 & 79 \\
\hline Core-4 & 5 & 16 & 18 & 38 & 6 & 3 & 71 & 95 & 78 & 73 & 90 & 74 \\
\hline Core-5 & 15 & 25 & 16 & 19 & 10 & 2 & 72 & 95 & 79 & 84 & 95 & 75 \\
\hline Core-6 & 33 & 19 & 15 & 23 & 1 & 3 & 68 & 95 & 91 & 79 & 89 & 74 \\
\hline Core-7 & 15 & 19 & 12 & 20 & 5 & 1 & 70 & 95 & 90 & 78 & 85 & 72 \\
\hline Core-8 & 12 & 15 & 10 & 15 & 5 & 1 & 75 & 95 & 90 & 75 & 84 & 72 \\
\hline Core-9 & 16 & 24 & 17 & 8 & 2 & 1 & 75 & 95 & 80 & 91 & 93 & 75 \\
\hline Core-10 & 6 & 31 & 18 & 17 & 5 & 1 & 72 & 96 & 71 & 89 & 93 & 75 \\
\hline Core-11 & 10 & 28 & 18 & 13 & 18 & 1 & 79 & 95 & 73 & 91 & 90 & 66 \\
\hline Core-12 & 9 & 19 & 15 & 15 & 17 & 1 & 70 & 93 & 69 & 89 & 87 & 60 \\
\hline
\end{tabular}

When the LIBS analysis results were examined, it was observed that the elements such as Fe, $\mathrm{Al}, \mathrm{Ca}, \mathrm{K}, \mathrm{Mg}$ and $\mathrm{Na}$ which are in the natural structure of the soil, had a higher percentage. The LIBS results of the same elements have been compared with the ICP-OES results, it has been observed that the elements with high percentage in the LIBS analysis are high concentration values in the ICP-OES results (Figure 2 and 3). 


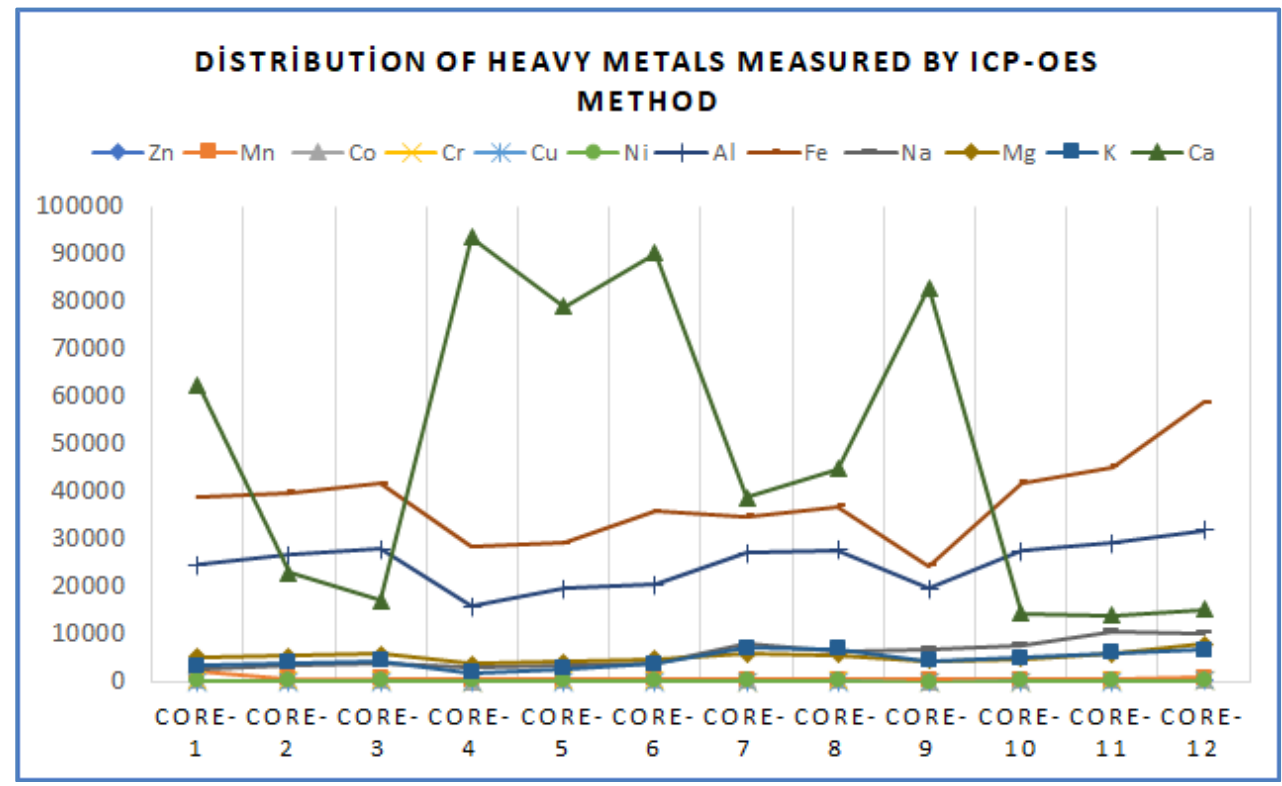

Figure 2. ICP-OES analysis results of core samples

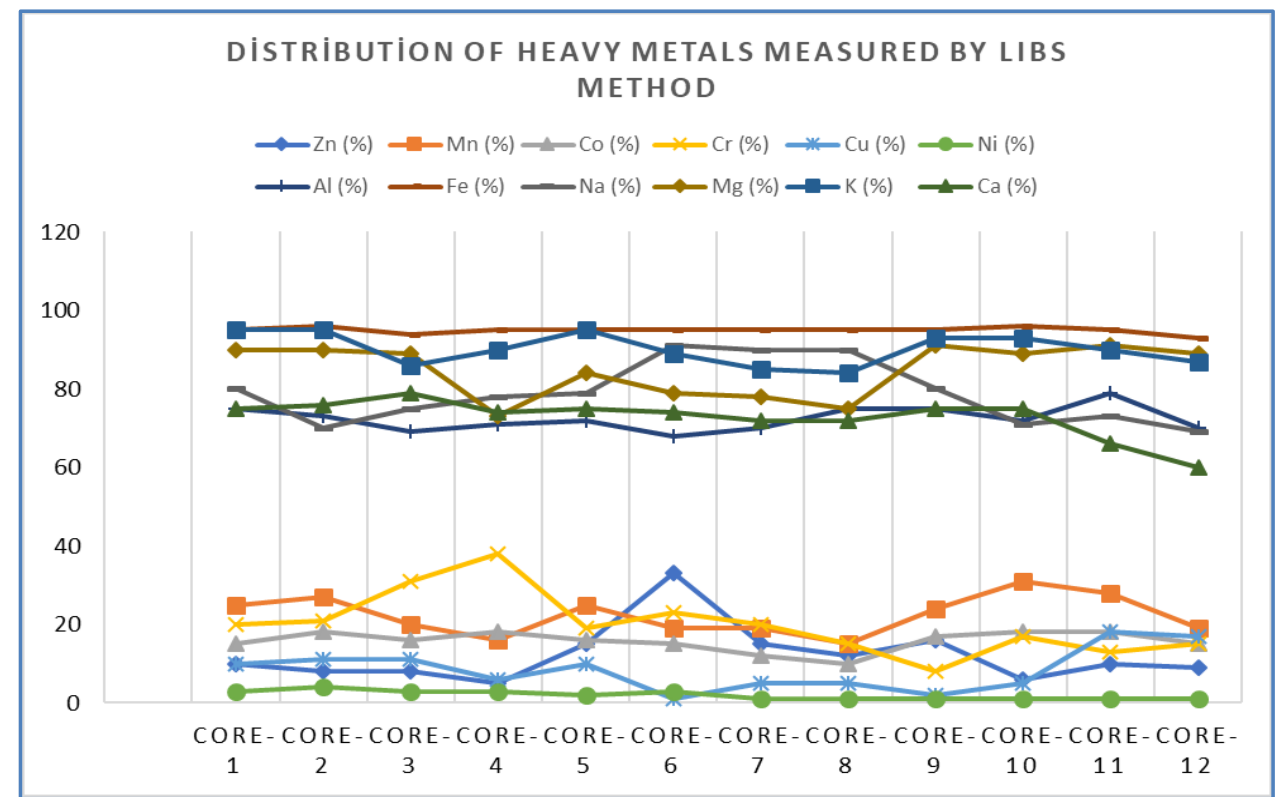

Figure 3. LIBS analysis results of core samples

In addition, the LIBS method; It has also shown important results in the determination of toxic elements such as $\mathrm{Cr}$, $\mathrm{Co}$ and $\mathrm{Cu}$ which increased in sea sediment with anthropogenic factors (Figure 3).

\section{Conclusions}

Results obtained in this work show that the LIBS technique applied to the determination of several heavy metals in soils is successful for the qualitative recognition of metal species but is still to be considered semiquantitative when the metal concentration values have to be 
measured. As a result of this study, it was revealed that LIBS method is a new method according to ICP-OES method. Despite its some drawbacks, LIBS can be considered a promising analytical technique for its intrinsic advantages. The presence of the elements present in the sample by the LIBS method is determined by a probability defined by\%. In contrast, the analysis does not provide the amounts of elements in the sample. Although this is seen as a disadvantage, this method gives very useful results for practical and preliminary investigations.

In this study, when the analysis results were examined, it has been seen that the elements ( $\mathrm{Fe}$, $\mathrm{Zn}, \mathrm{Al}, \mathrm{Mn}, \mathrm{Co}, \mathrm{Cr}, \mathrm{Cu}, \mathrm{Ni}, \mathrm{Na}, \mathrm{Mg}, \mathrm{K}, \mathrm{Ca}$ ) determined by ICP-OES analysis were also determined by LIBS method. In the analyzes made by ICP-OES method, the amounts of the elements in ppm are determined, while the results of LIBS analysis show the presence of the element only in\%. If analyzes are carried out to determine the origins of the elements present in the environment, the LIBS method is an important technique for determining the elements that are enriched with anthropogenic factors as well as the elements resulting from natural processes.

\section{References}

[1] Nicholson, F.A., Smith, S.R., Alloway, B.J., Carlton-Smith, C., Chambers, B.J., “An inventory of metals inputs to agricultural soils in England and Wales”, The Science of the Total Environment, 311 (2003) : 205-219.

[2] Wisbrun, R., Schechter, I., Niessner, R., Schroeder, H., Kompa, K.L., "Detector for trace element analysis of solid. Environmental samples by laser plasma spectroscopy", Anal. Chem. 66 (1994) : 2964-2975.

[3] Ciucci, A., Palleschi, V., Rastelli, S., Barbini, R., Colao, F., Fantoni, R., Palucci, A., Ribezzo, S., van der Steen, H.J.L., "Trace pollutants in soil by a time-resolved laser induced breakdown spectroscopy technique”, Appl. Phys. B 63 (1996) : 185-190.

[4] Eppler, A.S., Cremers, D.A., Hickmott, D.D., Ferris, M.J., Koskelo, A.C., "Matrix effects in the detection of $\mathrm{Pb}$ and $\mathrm{Ba}$ in soils using laser-induced breakdown spectroscopy”, Appl. Spectrosc. 509 (1996) 1175-1181.

[5] Cremers D.A., Yueh F.Y., Singh J.P., Zhang H., "Laser-induced breakdown spectroscopy, elemental analysis”, Encycl. Anal. Chem. (2006).

[6] Capitelli F., Colao F., Provenzano M.R., Fantoni R., Brunetti G., Senesi N., "Determination of heavy metals in soils by Laser Induced Breakdown Spectroscopy", Geoderma 106 (2002) : 45-62.

[7] Radziemsky, L.J., Loree, T.R., Cremers, D.A., "Laser-induced breakdown spectroscopy LIBS.: A new spectroscopical technique”, In: Killinge, D.K., Mooradian, A. Eds., Optical and Laser-Remote Sensing. Springer, New York, Chap. 7.3. (1983) : 273-298.

[8] Moenke-Blankenburg, L., “Laser Microanalysis”, Wiley, New York, Chap. 3. (1989) : 64-65. NIST Electronic Database, http:rrphyslab.nist.govrPhysRefDatarcontentsatomic.html.

[9] Radziemsky, L.J., Cremers, D.A., "Spectrochemical analysis using laser plasma excitation”, In: Radziemsk, L.J., Cremers, D.A. Eds.., Laser-Induced Plasmas and Applications. Marcel Dekker, New York, Chap. 7. (1989) : 295-325. 
[10] Velioğlu, M.H., Sezer, B., Bilge, G., Baytur, S.E., Boyacı, İ.H., "Identification of offal adulteration in beef by laser induced breakdown spectroscopy”, Meat Science 138 (2018) : 28-33.

[11] Dockery, C.R., Goode, S.R., "Laser-induced Breakdown Spectrocopy for the detection of gunshot residues on the hands of a shooter”, Appl Opt. 42(30) (2003) : 6153-8.

[12] Almessiere, M.A., Altuwiriqi, R., Gondal, M.A., Aldakheal, R.K., Alotaibi, H.F., "Qualitative and quantitative analysis of human nails to find correlation between nutrients and vitamin D deficiency using LIBS and ICP-AES”, Talanta 185 (2018) : 6170 .

[13] Anzano, J.M., Villoria, M.A., Ruíz-Medina, A., Lasheras, R.J., “Laser-induced breakdown spectroscopy for quantitative spectrochemical analysis of geological materials: Effects of the matrix and simultaneous determination”, Analytical Chimica Acta 575 (2) (2006) : 230-235.

[14] Samek, O., Krzyžánek, V., Beddows, D.C., Telle, H.H., Kaiser, J., Liška, M., “In: material identification using laser spectroscopy and pattern recognition algorithms", International Conference on Computer Analysis of Images and Patterns, Springer, Berlin (2001) : 443-450.

[15] Vadillo, J.M., Cardell, K., Cremers, D.A., Laserna, J.J., "Rapid screening method for heavy metals in contaminated soils using LIBS”, Quimica Analytica, 18 (1999) : 169174.

[16] Senesi, G.S., Baldassarre, G., Senesi, N., Radina, B., "Trace element inputs into soils by anthropogenic activities and implications for human health”, Chemosphere 39, (1999) : 343-377.

[17] Yümün, Z.Ü., "The effect of heavy metal pollution on foraminifera in the western Marmara Sea (Turkey)”, Journal of African earth Science 129 (2017) : 346-365.

[18] Yümün, Z.Ü., Önce, M., "Monitoring heavy metal pollution in foraminifera from the Gulf of Edremit (northeastern Aegean Sea) between Izmir, Balıkesir and Çanakkale (Turkey)”, Journal of African Earth Sciences. 130 (2017) : 110-124.

[19] Kam, E., Önce, M., "Pollutıon potential of heavy metals in the current sea sediments between Bandırma (Balıkesir) and Lapseki (Çanakkale) in the Marmara sea”, Journal of Engineering Technology and Applied Sciences. 3 (2016) : 141-148.

[20] Barbini, R., Colao, F., Fantoni, R., Palucci, A., Capitelli, F., “Application of laser induced breakdown spectroscopy to the analysis of metals in soils”, Appl. Phys. A 69 (1999) : S175-S179 Supp. 1.

[21] Yang, N., "Elemental analysis of soil using laser-induced Breakdown spectroscopy . University of Tennessee. master theses (2009).

[22] Pandhija, S., Rai, N.K., Rai, A.K., Thankur, S.N., "Contaminant concentration in enviromental samples using LIBS and CF-LIBS”, Applied Physics B 98 (2010) : 231241. 